\title{
ACADEMIAE HAUNIENSI
}

\author{
B. G. NIEBUHRIUS.
}

Q uam secutus rationem Vobis potissimum, viri clarissimi, inscribendam esse statuerim hanc Byzantini corporis partem, id paucis exponi, Vobisque, nisi admodum fallor, probari poterit. Societates eruditae, ad culturam incrementaque doctrinae institutae, in civitate litterata, quae cuique nationi propria est, Senatus locum tenere mihi videntur, quem vel peregrinis adire liceat, ut, quoties opus sit, ad auxilium ferendum hortentur, pro beneficiis acceptis gratias agant, egregie facta collaudent. Atque hoc quidem si vel cuivis peregrino facere licet, quanto id magis a Vobis, viri clarissimi, mihi concedi oportet, qui nascendi iure, munerumque in re publica cum civium plausu olim gestorum memoria, fretus, popularem vestrum me ferre nun- 
quam desinam, quem denique Vos collegii vestri honore dignum esse censuistis? Iam primum autem in limine operis quod Reiskiani commentarii parte inedita ornabitur, praedicanda mihi est memoria Sуна11. Qui quum sapienter intelligeret quam pretiosae essent schedae viri summi, quem plerique eius aevi homines eruditi superbe atque imperite despiciebant, eas, munifice a vidua redemtas, bibliothecae suae paravit, litterarumque commodo servavit: servavit dico: etenim in tanta quae subsecuta est tempestate atque rerum conversione, nisi vir ille ceteris dissimilis fuisset, labores Reiskii aut interiissent plane, aut fortasse, vili, si ficri posset, pretio coempti, Dibdino aliquo agente, in Lucullorum bibliothecas detrusi essent, unde negant redire quicquam quod semel sepuleris istis illatum sit. Male sit vobis, malae tenebrae Orci! Nunc autem plane contraria ratione evenit, ut post aliquot annos cum reliquis copiis Suhmianis in bibliothecam Regiam Hauniensem migrarent; huiusmodi divitiis ornari dignissimam; quippe quae splendore codicum praesertim qui ad litteras graecas orien- 
talesque pertinent ceteris per septentrionis regiones positis praefulget fere omnibus. Iam vero quum talis sit, peregrini quoque pariter cum civibus liberrimo ad eius thesauros gaudent aditu: verumtamen vestrates, quae maiorum fortuna et sapientia bibliothecis intulit, gnaviter eruunt ipsi, publicaeque luci atque utilitati tradunt. Hinc praeclaram in Germania atque in universum apud cunctos bonae doctrinae aestimatores aequos et peritos sibi laudem peperit O. D. BLоснгUS, qui, prolatis Herodiani Galenique libris, inter illos censetur qui reductis peculiari saeculi nostri felicitate in vilam libris veterum, communes extiterunt philologorum benefactores: non minus insignis acumine ingenii doctrinaeque praestantia, dum depravatam unici codicis scriptionem emendat. Eum igitur per litteras adii, simulac de edendis Reiskianis cogitationem susceperam, idque eo magis quod, propter tot annorum absentiam, parum gnarus mutationum quaie interea accidissent, nescio quomodo mihi persuaseram adscriptum esse Regiae bibliothecae Virum clarissimum. Bespondit ille comiter atque 
amice, pro more ingenii; meque, non esse provinciam suam 'quam autumabam, edocuit, commendavit autem ad perficienda quae cuperem, SALOMONIDEM. Qui laborem haud cunctanter susceptum quam sedulo, quam accurate executus sit, quam strenue enisus ut, sublatis mendis plurimis quae festinanti Reiskio adhaeserant, limatius ipso archetjpo prodiret quod mihi comparabat exemplum, quot eruditionis in universo negotio ediderit documenta, longum foret enarrare; silere de iuvenis egregii meritis, nefas. Reiskiani libri usum liberrimum, ut is tam accurate posset transcribi, concessit WERLAU FIUS, $\boldsymbol{V}$. cl.: cui rationes meas dignas videri quas adiuvet, et laetor, et inprimis mihi honorificum esse duco; eumque rogo, ut gratias quam amplissimas sibi agi sinat; meque de tali moderatore gratulantem bibliothecae, quam vetere amore amplector, aequis auribus audiat. Vos autem, viri clarissimi, valete, favoremque quo me ornastis, servate mihi perpetuum. 